\title{
Multimodal Management of Atrophic Acne Scarring in the Aging Face
}

\author{
T. Gerald O'Daniel
}

Received: 28 October 2010/Accepted: 17 February 2011/Published online: 14 April 2011

(C) The Author(s) 2011. This article is published with open access at Springerlink.com

\begin{abstract}
Atrophic facial acne scarring is a widely prevalent condition that can have a negative impact on a patient's quality of life. The appearance of these scars is often worsened by the normal effects of aging. A number of options are available for the treatment of acne scarring, including chemical peeling, dermabrasion, ablative or nonablative laser resurfacing, dermal fillers, and surgical techniques such as subcision or punch excision. Depending on the type and extent of scarring, a multimodal approach is generally necessary to provide satisfactory results. Resurfacing techniques correct surface irregularities, long-lasting dermal fillers address the volume loss resulting from acne, and sub-superficial musculoaponeurotic system (SMAS) face-lift procedures counter the soft tissue laxity and ptosis associated with aging. This article briefly reviews the evolution of individual approaches to treating atrophic acne scarring, followed by case examples illustrating results that can be achieved using a multimodal approach. Representative cases from patients in their $30 \mathrm{~s}, 40 \mathrm{~s}$, and $50 \mathrm{~s}$ are presented. In the author's clinical practice, multimodal approaches incorporating fractionated laser, injectable poly-L-lactic acid, and sub-SMAS face-lift procedures have achieved optimal aesthetic outcomes, high patient satisfaction, and durability of aesthetic effect over time.
\end{abstract}

Keywords Acne scarring - Aging - Resurfacing - Dermal fillers $\cdot$ Poly-L-lactic acid $\cdot$ Face-lift

T. Gerald O'Daniel ( $\square)$

Division of Plastic Surgery, University of Louisville

School of Medicine, Louisville, KY, USA

e-mail: jerry.odaniel@gmail.com

T. Gerald O'Daniel

222 South First Street, Suite 100, Louisville, KY 40202, USA
Acne is one of the most common skin conditions experienced by adolescents and adults. Reported prevalence rates vary from $35 \%$ to more than $90 \%$ in adolescents [1], while a community-based study in adults aged $>25$ years reported overall prevalence rates of $54 \%$ in women and $40 \%$ in men [2]. In a more recent survey of adults aged $\geq 20$ years, $73.3 \%$ reported ever having acne, and rates of current acne were higher in women than in men across different age groups, from 50.9\%/42.5\% (women/men) in those aged 20-29 years to $15.3 \% / 7.3 \%$ in those aged $\geq 50$ years [3]. In a study of patients selected from acne clinics, at least some degree of facial scarring was identified in $95 \%$ of cases [4]. Acne scarring can be deeply distressing to patients, often resulting in decreased self-esteem and a diminished quality of life [5].

Unfortunately, acne scarring also can be a difficult problem to address satisfactorily, usually requiring the use of several different treatment modalities over multiple treatment sessions [6-8]. The challenge stems in part from the variability of scars in each individual patient and from patient to patient. Depending on the degree of acneinduced inflammation and atrophic effects, individual scars can vary widely in type, depth, and extent, with different scars requiring different treatment approaches [6]. Compounding the problem, many of the established treatment approaches for acne scarring have been associated with substantial morbidity and recuperation time [6,9]. A further challenge stems from the fact that facial aging often exacerbates the effects of acne scarring. Inflammation associated with moderate to severe acne can result in dermal collagen and fat loss, leading to atrophic scarring [8]. Similarly, aging itself is associated with fat loss, magnifying the effects of acne scarring. When facial skin begins to sag as a natural consequence of aging, it becomes suspended on old fibrotic acne scars. This tends to produce an irregular cascading appearance. Thus, patients with 
long-standing acne scarring may not seek treatment until their $30 \mathrm{~s}, 40 \mathrm{~s}$, or $50 \mathrm{~s}$, as age begins to worsen the appearance of the scarring [9].

This article briefly discusses the physiological changes associated with atrophic acne scars and the aging face, and reviews the evolution of treatment modalities for this patient population. Case examples from the author's practice will be used to illustrate a multimodal treatment approach that have been successful in treating acne scarring and aging face for patients of different age groups. This approach generally combines laser resurfacing, polyL-lactic acid (PLLA) injection, and sub-superficial musculoaponeurotic system (SMAS) face-lift procedures.

\section{Overview of Acne Scarring}

Types of acne scars include keloid, hypertrophic, and atrophic. Atrophic acne scarring is by far the most common form, especially on the face [6]. Atrophic acne scars can be broadly categorized as rolling, ice-pick, shallow boxcar, or deep boxcar (Table 1) [10, 11]. Histologically, atrophic acne scars exhibit thinning of the skin and loss of collagen, elastin, and deep dermal fat resulting in a downward pull of the epidermis [12]. In the case of deep cystic acne lesions, inflammatory mediators destroy facial fat while the size of the lesion itself can leave a void after its involution that cannot be filled by surrounding subcutaneous tissues. Rather, the tissues may be drawn in from surface layers, an effect worsened by the contracture of the scarring around the cysts. In such cases, a patient's appearance can actually worsen after the cystic acne is brought under control by isotretinoin or other successful treatments [6].

\section{Treatment Options for Management of Atrophic Acne Scarring}

Because of the varying types and severity of acne scarring, it is important to keep in mind that the management of scarring in any individual patient will likely require some combination of techniques: resurfacing techniques to address superficial irregularities; dermal fillers to replace lost volume in large atrophic areas; surgical procedures such as punch excision to remove deep boxcar or large icepick scars; and face-lift procedures to restore facial shape and tighten the skin in older patients in whom facial aging is magnifying the effects of acne scarring. Figure 1 illustrates the effects of facial aging on acne scars. Figure 1a was taken at age 46 with mild acne scarring visible on the cheek and temple. Figure $1 \mathrm{~b}$ is the same patient 10 years later. The laxity of skin due to aging is apparent and the acne scarring has become more prominent. Figure 1c was taken 4 months after a face-lift with simultaneous subdermal injection of 1 vial of injectable PLLA (Sculptra ${ }^{\circledR}$, Dermik Laboratories, Bridgewater, NJ) to each side of the face. In this series of photographs, no resurfacing procedures were performed. As discussed in additional detail in the Dermal Filler subsection, it is this author's preference to use injectable PLLA (prepared and injected as described) as the dermal filler of choice to treat acne scarring in the aging face. The preparation of injectable PLLA involves reconstituting each vial of product with $8 \mathrm{ml}$ of normal saline (without lidocaine) and allowing at least $24 \mathrm{~h}$ but less than $72 \mathrm{~h}$ for complete product hydration before use. Injectable PLLA is injected in a grid-like pattern into the subdermal and deep dermal planes during a face-lift procedure, with greater volume injected into areas with the greatest lipoatrophy. Post procedure massage is not performed over the treated area.

\section{Resurfacing Techniques}

Historically, acne scarring has been treated by chemical peeling for superficial scars and dermabrasion for deeper scars [13]. The application of trichloroacetic acid (TCA) to the skin causes epidermal cellular necrosis and necrosis of collagen in the papillary to upper reticular dermis, depending on the concentration of TCA. Following a TCA peel, the skin reepithelializes during the next several days

Table 1 Global acne scarring classification: type of scars making up the classification grades

\begin{tabular}{lll}
\hline $\begin{array}{l}\text { Grade } \\
\text { disease }\end{array}$ & $\begin{array}{l}\text { Level of } \\
\text { Example of scars }\end{array}$ \\
\hline 1 & Macular & $\begin{array}{c}\text { Erythematous, hyper-, or hypo pigmented flat marks; a problem of color rather than contour; visible to the patient or } \\
\text { observer at any distance } \\
\text { Mild rolling, small soft papular; may not be obvious at social distances of } \geq 50 \mathrm{~cm} \text {; may be covered adequately by } \\
\text { makeup or shadow of shaved beard hair in men }\end{array}$ \\
3 & Mild & $\begin{array}{c}\text { More significant rolling, shallow boxcar, mild to moderate hypertrophic or papular scars; obvious at social distances of } \\
50 \text { cm, not easily covered, able to be flattened by manual stretching of the skin (if atrophic) }\end{array}$ \\
4 & Severe & $\begin{array}{c}\text { Punched out atrophic (deep boxcar), ice pick, bridges and tunnels, marked atrophy, dystrophic significant hypertrophy or } \\
\text { keloid; obvious at social distances, not easily covered, and not able to be flattened by manual stretching of the skin }\end{array}$
\end{tabular}

Reprinted with permission from [9] 
Fig. 1 a Mild acne scarring in a 46-year-old woman. b Same patient 10 years later (age $=56)$ illustrating the effects of facial aging and acne scarring. c Four months after a face-lift procedure with simultaneous subdermal placement of injectable PLLA
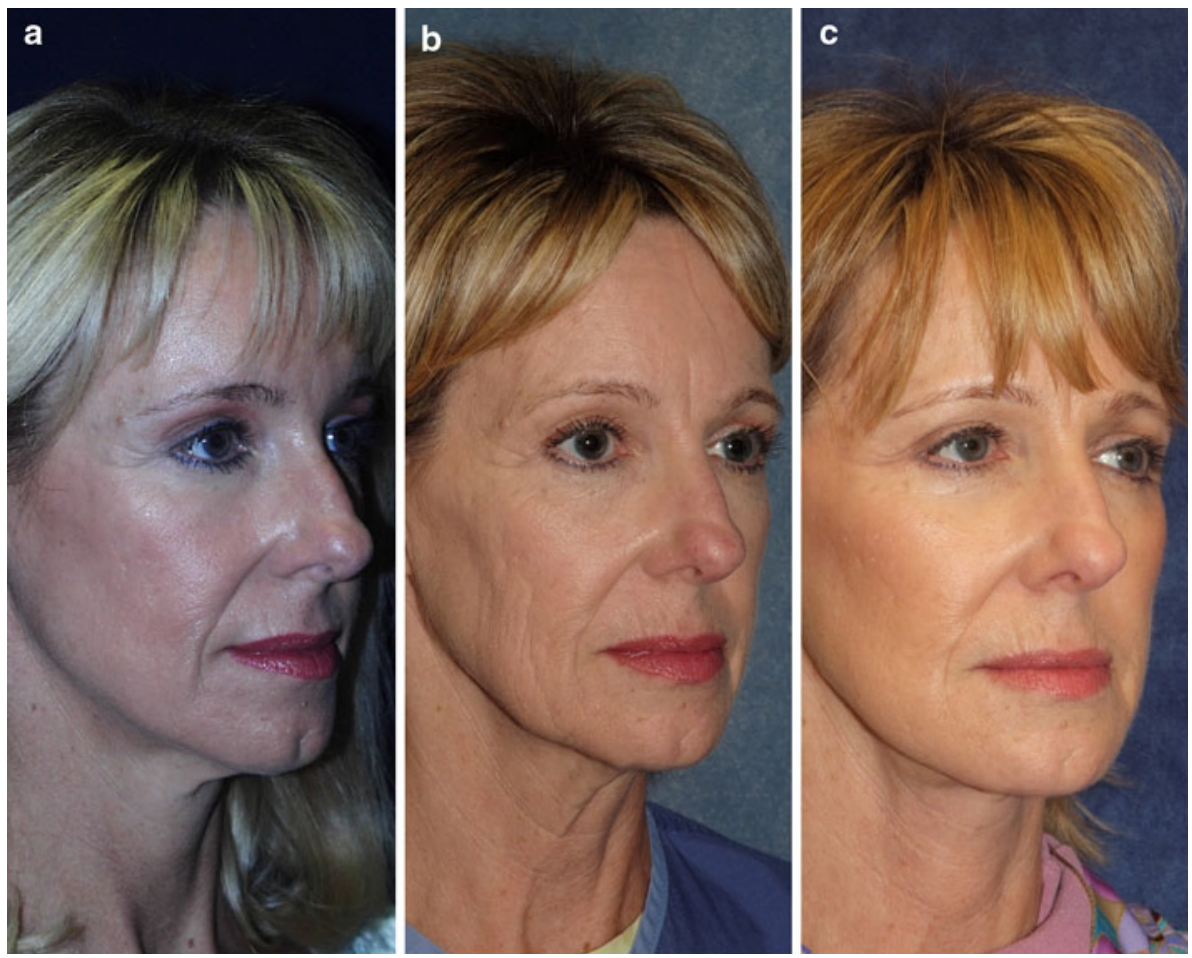

and dermal collagen remodeling may continue for several months [12, 14]. This technique has been refined for treatment of atrophic acne scars using the Chemical Reconstruction Of Skin Scars (CROSS) method, which employs focal application of high-concentration TCA (65 or $100 \%)[12,15]$. The CROSS method is reported to produce improved clinical results with rapid healing time and lower complication rates [14]. Dermabrasion techniques also have been refined over the years, evolving from the use of sandpaper to mechanical devices such as serrated wheels or diamond-embedded fraises that deliver steady, even abrasion; however, they remain very operatordependent [6].

Even with these innovations, mechanical and chemical ablative techniques have largely been overtaken by ablative or nonablative laser techniques for resurfacing, which are technically easier to perform and tend to produce less variable results [6]. Ablative laser skin resurfacing for atrophic acne scars has been performed successfully with far-infrared $\mathrm{CO}_{2}$ or erbium:yttrium-aluminum-garnet laser systems. These methods selectively target water-containing tissue of the epidermis and dermis, causing reproducible degrees of skin vaporization and stimulating wound remodeling with new collagen and elastin formation $[16,17]$. While $\mathrm{CO}_{2}$ lasers are very effective in treating acne scarring, they are also the most operator-dependent of the newer generation of ablative methods and techniques vary based on personal experience [10]. Fully ablative resurfacing techniques are often associated with swelling, burning discomfort, oozing, and crusting of the face, as well as significant downtime (1-2 weeks) for the patient. There is also a risk of prolonged postoperative erythema after initial healing (lasting weeks or months), permanent hypopigmentation, infection, and occasionally fibrosis and scarring [16-18]. Due to these potential complications, patients are becoming less willing to choose fully ablative laser therapy, and these techniques are now giving way to nonablative or partially ablative laser therapies that stimulate collagen remodeling while minimally disrupting the epidermis.

The first method shown to induce dermal fibroblasts to produce new collagen without damaging the epidermis employed a 585-nm pulsed dye laser (PDL) that targeted hemoglobin to create a thermal insult to the dermal microvasculature $[17,19]$. Postoperative purpura persisting for several days has somewhat limited the usefulness of PDL in treating acne scarring [17]. Newer nonablative laser or light-based systems include the 1064- and 1320-nm neodymium-doped (Nd):YAG, 1450-nm diode, and 1540-nm erbium glass lasers, and intense pulsed light systems [18]. These techniques combine epidermal surface cooling with longer wavelengths that penetrate to the dermal layer to create a controlled thermal injury. In small studies of the 1064-nm Nd:YAG laser for the treatment of atrophic scars, most patients showed mild to moderate clinical improvement with significant increases in the number and density of collagen fibers; adverse events were limited to mild transient erythema and increased skin 
sensitivity $[20,21]$. In a similar study comparing the 1320-nm Nd:YAG and 1450-nm diode lasers, it was found that both of these methods were similarly effective and associated with mild to moderate clinical improvements in atrophic acne scarring [17].

Fractional photothermolysis is a further innovation in resurfacing technique that was developed in response to the safety concerns of full ablative therapies and the modest efficacy results demonstrated for the nonablative therapies discussed above [18, 22]. This technique is based on the creation of spatially precise microscopic thermal zones (MTZs) at depths of $200-500 \mu \mathrm{m}$ and spaced at 200-300 $\mu \mathrm{m}$ intervals, leaving surrounding tissue intact [18]. It was first described using a 1550-nm erbium fiber laser $\left(\right.$ Fraxel $^{\circledR}$, Solta Medical Inc., Hayward, CA), although other fractional laser devices are now available [22]. This method differs from other resurfacing techniques in that damaged epidermal components are extruded by viable keratinocytes at the lateral margins of the MTZs and exfoliated after several days (lending the skin a bronzed appearance), epidermal tissue that is spared between thermal zones contains viable cells capable of rapid reepithelialization, and the stratum corneum remains intact immediately after treatment due to its low water content. The gradual exfoliation of the epidermis following fractional resurfacing also results in improved superficial dyspigmentation. This technique generally requires a series of three to six treatments at 2-4 week intervals for best clinical improvement, which can achieve results for atrophic scars similar to that of traditional ablative laser skin resurfacing. In contrast to ablative techniques, adverse effects are typically mild and transient, including erythema, periocular edema, and a slight bronzing of the skin [18].

\section{Dermal Fillers}

The goal of using dermal fillers in the treatment of atrophic acne scarring is to replace volume lost by the atrophic effects of the acne. As such, the ideal agent would be one that restores volume to the defect by stimulating the surrounding tissue to replace collagen for a long-lasting effect, as opposed to those that provide a short-term effect based on the volume of injected resorbable material. Based on the experience of the author and other published sources, injectable collagens and many of the available hyaluronic acid (HA) preparations are too short-lived (approximately 3-6 months $[10,23])$ to appropriately treat moderate to severe acne scars, and use of such products for this purpose would require a significant total injection volume over time with frequent retreatments, contributing to greater total cost and time commitment for the patient. Less viscous forms of HA, such as Restylane ${ }^{\circledR}$ (Medicis Aesthetics, Scottsdale, AZ) or Juvederm ${ }^{\circledR}$ (Allergan, Santa Barbara,
CA), may be appropriate for patients with mild atrophic scars [9].

Autologous fat transplantation has been proven successful in the treatment of acne scarring, and has the advantage of complete biocompatibility [24]. Grafted fat has the potential for long-term correction if it is handled atraumatically and the proper harvesting/grafting technique is followed, but it also has proved unpredictable in the hands of many surgeons [24]. Many factors are involved in the survival of autologous fat, such as harvest site selection and technique, recipient site and injection technique, methods of processing, temperature and duration of fat storage, and patient age [25]. Other potential disadvantages of this treatment modality include unpredictable subdermal placement and creation of a second surgical site to harvest the fat.

Longer-acting dermal fillers have the advantage of predictably longer persistence and may be appropriate for larger areas characteristic of rolling scars. Calcium hydroxylapatite and injectable PLLA are two longer-acting products that have published information on their use for atrophic acne scarring. Calcium hydroxylapatite (Radiesse $^{\circledR}$, BioForm Medical, San Mateo, CA) was evaluated in a single-center, prospective, controlled trial of ten patients with acne scarring (including at least one saucerized scar) [26]. At the 12-month evaluation, three patients showed $>75 \%$ improvement and six patients experienced 50-75\% improvement in treated saucerized scars; one patient had $25-50 \%$ improvement in this type of scar. No patients showed improvement in ice-pick scars. Due to the shorter persistence of the product relative to injectable PLLA, the author does not use calcium hydroxylapatite in the multimodal approach to treating acne scarring that is described here.

Injectable PLLA was originally approved by the Food and Drug Administration for the treatment of lipoatrophy associated with treatment using highly active antiretroviral therapy (HAART) for human immunodeficiency virus infection. The results achieved with injectable PLLA in HAART-associated lipoatrophy led to its use in treating lipoatrophy associated with aging and acne scarring [27]. Although injectable PLLA has not been approved for treatment of acne scarring in the US, it is now approved for use in immune-competent people as a single regimen for correction of shallow to deep nasolabial fold contour deficiencies and other facial wrinkles [28]. Clinical benefits of injectable PLLA have been reported to persist for two years or longer $[27,29,30]$. Injectable PLLA has been studied in a single-center, open-label, prospective study conducted in 20 patients with facial scars resulting from moderate to severe acne or varicella [31]. In this study, the investigator reported significant reductions in severity of scars treated with injectable PLLA over the course of seven 
treatment sessions; at the seventh session, scar reduction reached a maximum of $46.4 \%(p<0.0001)$. The author of this study speculated that injectable PLLA corrected the acne scars by both subcision, in which the injection method severed the fibrous bands that tether the skin downward, and by stimulating collagen production, which pushes the skin upward. Injectable PLLA worked best for scars that were at least as broad as they were deep, and were no more than 2-3 mm deep, rather than small ice-pick scars.

Two recent case reports have further supported the clinical benefits associated with injectable PLLA for the treatment of atrophic acne scars [7, 8]. In a report on two female patients who each underwent three treatment sessions with injectable PLLA, both were extremely pleased with their results at 1- and 4-year follow-up evaluations [8]. In an additional report of a 60-year-old woman who had previously failed to achieve satisfactory results from $\mathrm{CO}_{2}$ laser resurfacing, dermabrasion, TCA peels, collagen, calcium hydroxylapatite, and HA dermal fillers, the patient noted observable improvements in her acne scars 6 months after her seventh treatment session with injectable PLLA [7]. This patient experienced minimal swelling (up to 3 days) and injection-site bruising (up to 7 days); injectable PLLA was well tolerated throughout the course of her treatment [7].

\section{Surgical Options}

Subcision and punch excision remain important surgical options for certain types of atrophic acne scars. Subcision, which can be useful in combination therapy for moderate levels of scarring, appears to work by breaking up the attachments of these scars under the skin and releasing the surface from deeper structures [9]. Punch techniques remain the gold standard for large, deep boxcar and icepick scars [9].

In addition to the direct treatments for acne scarring discussed in the preceding sections, face-lift procedures can be a valuable component of a multimodal approach to acne scarring-especially in patients approaching their fourth decade or older-by addressing the effects of facial aging that serve to magnify the appearance of the scars. Among other changes that occur with age, the diffuse and balanced distribution of superficial and deep fat that characterizes the youthful face is lost; soft tissue fullness is lost in certain areas, while persistence or hypertrophy of fat occurs in others. Face-lift procedures generally aim to restore the balanced distribution of facial fullness seen in youth, but conventional techniques utilize lifting and tightening to counteract the facial soft-tissue descent rather than fully addressing the issue of facial shape. Recently, however, there has been an evolution away from conventional excision and suspension procedures toward the use of conservative skin excision, deep fascial-SMAS manipulation, and volume restoration [32]. Incorporation of SMAS into face-lift procedures has represented a fundamental change in facial rejuvenation surgery [33, 34], and one advantage of this approach is that it avoids disruption of the subcutaneous plane. Because the subcutaneous plane is not disrupted, a dermal filler can be injected at the time of the face-lift procedure to provide soft tissue augmentation.

The face-lift technique favored by the author is a modification of the standard sub-SMAS operation, in which undermining of the skin is initially limited to the extent that the sub-SMAS plane can be entered and complete release of the underlying ligamentous attachments achieved. Elevation and fixation of the SMAS composite flap to the zygomatic arch and deep temporal fascia allow vertical repositioning of the malar fat pad. The skin is then further released from the SMAS composite flap, only to the point of releasing any visible tethering points, such as those resulting from acne scarring. The skin is redraped and excess skin excised. After skin closure, injectable PLLA, prepared according to the procedure described previously, is injected into the deep subdermal plane to smooth the irregular skin surface. Injectable PLLA is placed so that deeper undulations of the skin receive a greater volume of injected material than the surrounding rims of the scars.

While each of the described procedures used individually can produce very satisfactory results, especially in younger patients with milder acne scarring, this author has found that the combination of multiple modalities is often necessary to optimize outcomes. The following case examples illustrate the level of aesthetic correction that can be achieved by a multimodal approach to acne scarring. Each case example shows a patient in a different decade of life.

\section{Case Examples}

\section{Patients Aged 30-40 Years}

In the 30-40-year-old patient, the atrophic component of the scar is accentuated by early facial volume shifts and subtle laxity of skin. This is more apparent in a thinner patient because of the lower initial volume of facial fat compared with that in an overweight patient. This case example (Fig. 2a, b) shows a 40-year-old woman with long-standing, grade 3 acne scarring who requested treatment of the lower third of her face. Additionally, she sought improvement in the overall quality of her skin. The photographs on the left of each figure show the patient during the initial evaluation before any procedures were performed. The patient was seen again 2 months prior to surgery, at which time two vials of injectable PLLA 
a
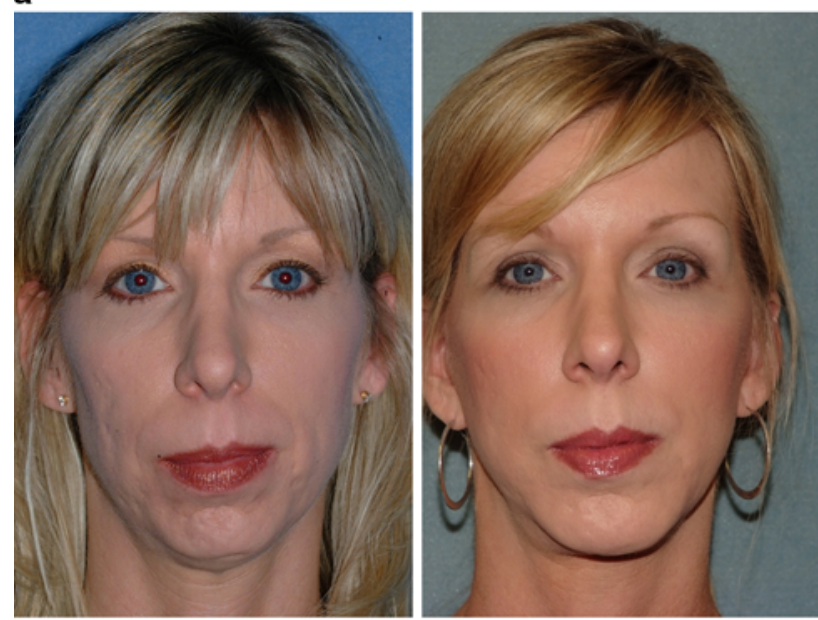

b
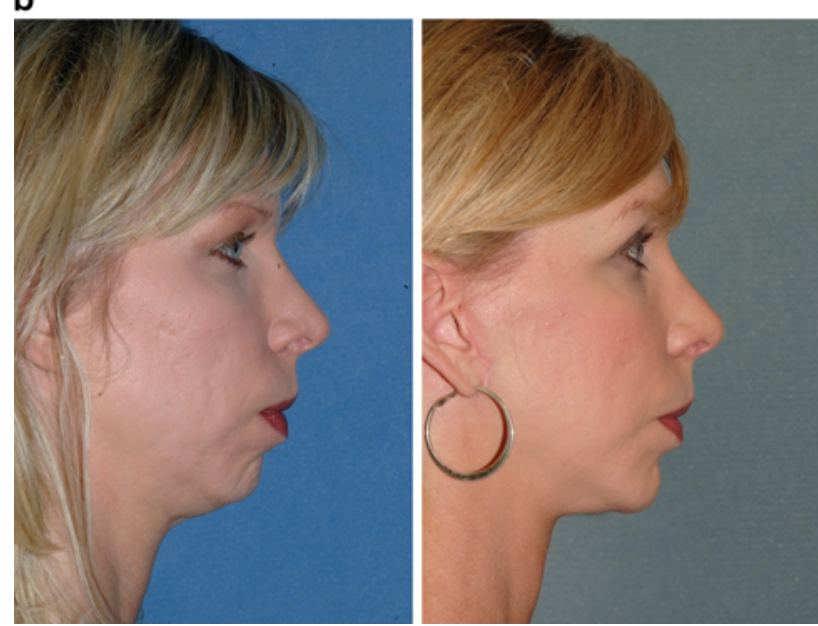

Fig. 2 a An example of a 30-40-year-old patient before (left) and after (right) treatment with multiple modalities, including surgery, dermal filler, and nonablative laser. b A profile view of the patient before (left) and after (right) the procedures

(reconstituted and hydrated as described previously) were injected into the submalar cheeks and jawline for volume restoration. A short-scar face-lift was performed in addition to a platysmal corset with subplatysmal suprahyoid fascial release and chin implant to achieve balance of her facial profile. Two vials of injectable PLLA were placed concomitantly with the face-lift. The injections were done in a grid-like manner with greater amounts placed in the depths of the atrophic scars. After 8 weeks, the patient was treated with a nonablative erbium fiber laser (Fraxel Re:store ${ }^{\circledR}$, Solta Medical Inc.) for superficial skin irregularities. The postoperative photos on the right side of Fig. 2a and b were taken 18 months after the procedures.

Patients Aged 40-50 Years

The next case example is a 46-year-old woman with longstanding adult cystic acne that was unsuccessfully treated a
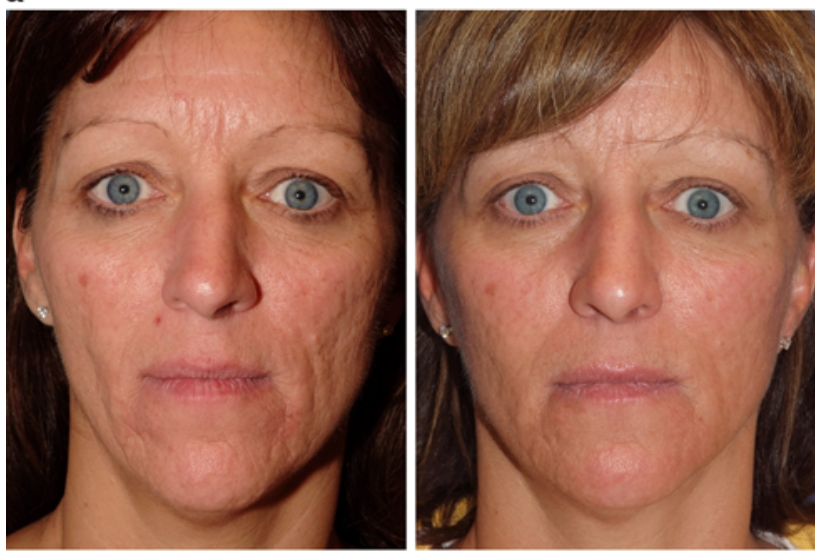

b
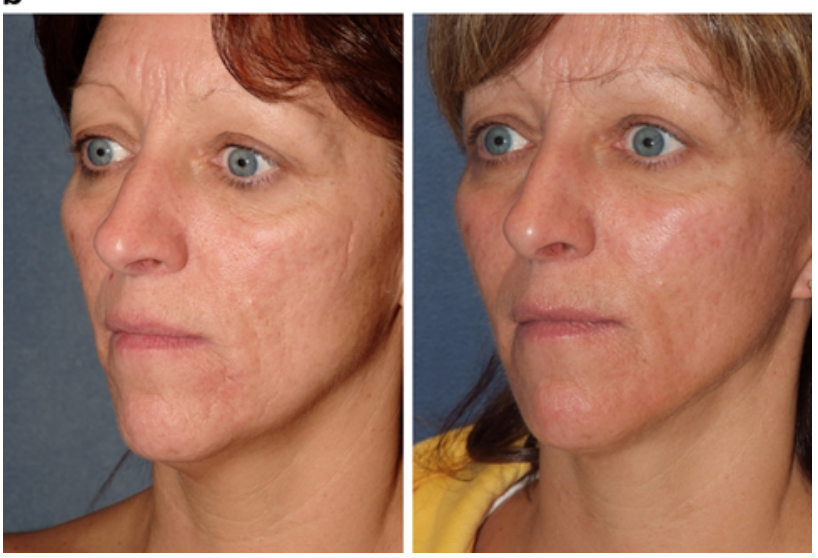

Fig. 3 a An example of a 40-50-year-old patient with atrophic acne scarring before (left) and after (right) multimodal treatment. b A $45^{\circ}$ view of the patient before (left) and after (right) the procedures

with conservative measures, topical agents, and oral antibiotics, and finally controlled with a 12-month course of isotretinoin. Several years after stabilization of the cystic component of her acne, she presented with concerns related to the grade 4 atrophic scars and facial aging (Fig. 3a, b). The patient was treated with a short-scar face-lift with concomitant injection of two vials of injectable PLLA (prepared as described previously) placed in the subdermal and deep dermal planes, with greater amounts placed in the depths of each scar. Six months after the face-lift procedure, she was treated with partial ablative resurfacing using a $\mathrm{CO}_{2}$ fractional laser (Lutronic USA, LLC, Princeton Junction, NJ). The postoperative photos were taken 18 months after the face-lift procedure (1 year after laser resurfacing).

\section{Patients Aged 50-60 Years}

The final case example (Fig. 4a, b) is a 55-year-old woman with long-standing, grade 3 and grade 4 acne scars after treatment with isotretinoin for cystic acne many years 
a
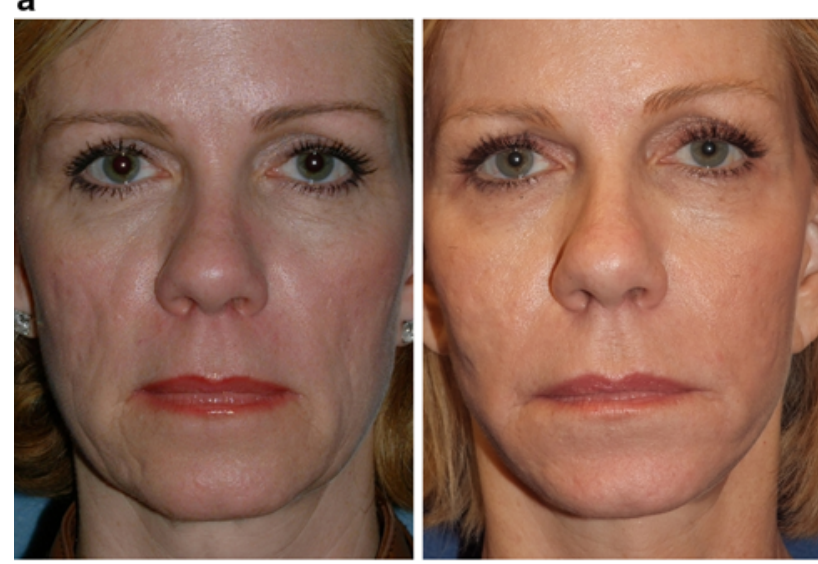

b
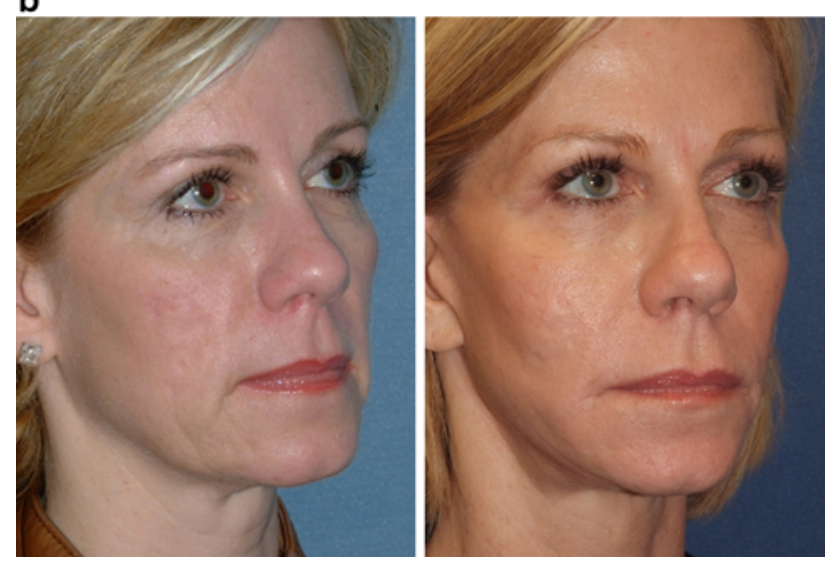

Fig. 4 a An example of a 50-60-year-old patient with high lean body mass and atrophic acne scars before (left) and after (right) multimodal treatment. b A $45^{\circ}$ view of the patient before (left) and after (right) dermal filler, full face-lift, and nonablative laser procedures

prior. She had a high lean body mass that accentuated the appearance of her atrophic acne scars. Two sessions of injectable PLLA (prepared as previously described) were performed 24 months prior to the face-lift procedure to address the facial lipoatrophy. A short-scar face-lift with concomitant injection of an additional two vials of injectable PLLA was followed by four treatments with a nonablative erbium fiber laser (Fraxel Re:store ${ }^{\circledR}$, Solta Medical Inc.). The photographs on the right side of the figure show the patient 20 months after the final resurfacing procedure. The combination of volume replacement, surgical repositioning, and resurfacing techniques led to an aesthetic improvement and a high level of patient satisfaction.

\section{Conclusions}

Both acne scarring and the normal aging process can result in the loss of dermal collagen and facial lipoatrophy, such that patients already suffering from the negative impact of facial acne scarring may find the appearance of these scars worsening over time as they approach their $40 \mathrm{~s}$ and $50 \mathrm{~s}$. Fortunately, treatment options for acne scarring have evolved from solely mechanical or chemical resurfacing techniques to multimodal approaches that can address multiple aspects of the aesthetic defect. Particularly in the aging face, optimal aesthetic outcomes can best be achieved using a multimodal approach, including resurfacing techniques to improve surface irregularities, longlasting dermal and subdermal fillers to replace lost facial volume, and face-lift procedures to reposition facial tissue. To date there have not been published reports of other multimodality treatment protocols for the treatment of the constellation of findings in a patient with aging face and atrophic acne. In the author's clinical experience, the combination of fractionated laser, injectable PLLA, and sub-SMAS face-lift has produced outstanding results for many patients with atrophic acne scarring in their third, fourth, or fifth decades.

Acknowledgments Editorial support for this article was provided by the editorial staff at Embryon. This article was funded by Dermik Laboratories, a business of sanofi-aventis U.S. LLC. The author gratefully acknowledges Marci Mikesell, $\mathrm{PhD}$, who assisted in the preparation of this article based on author-provided comments. The author was fully responsible for the content, editorial decisions, and opinions expressed in the current article. The author received no honoraria or other form of financial support related to the development of this manuscript.

Conflicts of interest The author has no financial conflicts of interest to report.

Open Access This article is distributed under the terms of the Creative Commons Attribution Noncommercial License which permits any noncommercial use, distribution, and reproduction in any medium, provided the original author(s) and source are credited.

\section{References}

1. Stathakis V, Kilkenny M, Marks R (1997) Descriptive epidemiology of acne vulgaris in the community. Australas J Dermatol 38:115-123

2. Goulden V, Stables GI, Cunliffe WJ (1999) Prevalence of facial acne in adults. J Am Acad Dermatol 41:577-580

3. Collier CN, Harper JC, Cantrell WC, Wang W, Foster KW, Elewski BE (2008) The prevalence of acne in adults 20 years and older. J Am Acad Dermatol 58:56-59

4. Layton AM, Henderson CA, Cunliffe WJ (1994) A clinical evaluation of acne scarring and its incidence. Clin Exp Dermatol 19:303-308

5. Loney T, Standage M, Lewis S (2008) Not just 'skin deep': psychosocial effects of dermatological-related social anxiety in a sample of acne patients. J Health Psychol 13:47-54

6. Goodman G (2003) Post acne scarring: a review. J Cosmet Laser Ther 5:77-95

7. Sadick NS, Palmisano L (2009) Case study involving use of injectable poly-L-lactic acid (PLLA) for acne scars. J Dermatolog Treat 20:302-307 
8. Sadove R (2009) Injectable poly-L-lactic acid: a novel sculpting agent for the treatment of dermal fat atrophy after severe acne. Aesthetic Plast Surg 33:113-116

9. Goodman GJ, Baron JA (2007) The management of post-acne scarring. Dermatol Surg 33:1175-1188

10. Alam M, Dover JS (2006) Treatment of acne scarring. Skin Therapy Lett 11:7-9

11. Jacob CI, Dover JS, Kaminer MS (2001) Acne scarring: a classification system and review of treatment options. J Am Acad Dermatol 45:109-117

12. Yug A, Lane JE, Howard MS, Kent DE (2006) Histologic study of depressed acne scars treated with serial high-concentration (95\%) trichloroacetic acid. Dermatol Surg 32:985-990

13. Gentile RD (2005) Multimodality aesthetic skin rejuvenation. Facial Plast Surg 21:120-130

14. Cho SB, Park CO, Chung WG, Lee KH, Lee JB, Chung KY (2006) Histometric and histochemical analysis of the effect of trichloroacetic acid concentration in the chemical reconstruction of skin scars method. Dermatol Surg 32:1231-1236

15. Lee JB, Chung WG, Kwahck H, Lee KH (2002) Focal treatment of acne scars with trichloroacetic acid: chemical reconstruction of skin scars method. Dermatol Surg 28:1017-1021

16. Chapas AM, Brightman L, Sukal S, Hale E, Daniel D, Bernstein LJ, Geronemus RG (2008) Successful treatment of acneiform scarring with $\mathrm{CO}_{2}$ ablative fractional resurfacing. Lasers Surg Med 40:381-386

17. Tanzi EL, Alster TS (2004) Comparison of a 1450-nm diode laser and a 1320-nm Nd:YAG laser in the treatment of atrophic facial scars: a prospective clinical and histologic study. Dermatol Surg 30:152-157

18. Tanzi EL, Wanitphakdeedecha R, Alster TS (2008) Fraxel laser indications and long-term follow-up. Aesthet Surg J 28:675-678

19. Patel N, Clement M (2002) Selective nonablative treatment of acne scarring with $585 \mathrm{~nm}$ flashlamp pulsed dye laser. Dermatol Surg 28:942-945

20. Friedman PM, Jih MH, Skover GR, Payonk GS, Kimyai-Asadi A, Geronemus RG (2004) Treatment of atrophic facial acne scars with the 1064-nm Q-switched Nd:YAG laser: six-month followup study. Arch Dermatol 140:1337-1341

21. Keller R, Belda JW, Valente NY, Rodrigues CJ (2007) Nonablative 1, 064-nm Nd:YAG laser for treating atrophic facial acne scars: histologic and clinical analysis. Dermatol Surg 33:1470-1476

22. Narurkar VA (2009) Nonablative fractional laser resurfacing. Dermatol Clin 27:473-478 vi

23. Buck DW 2nd, Alam M, Kim JY (2009) Injectable fillers for facial rejuvenation: a review. J Plast Reconstr Aesthet Surg 62:11-18

24. Coleman SR (2006) Structural fat grafting: more than a permanent filler. Plast Reconstr Surg 118(Suppl 3):108S-120S

25. Cooper JS, Lee BT (2009) Treatment of facial scarring: lasers, filler, and nonoperative techniques. Facial Plast Surg 25:311-315

26. Goldberg DJ, Amin S, Hussain M (2006) Acne scar correction using calcium hydroxylapatite in a carrier-based gel. J Cosmet Laser Ther 8:134-136

27. Hanke CW, Redbord KP (2007) Safety and efficacy of poly-Llactic acid in HIV lipoatrophy and lipoatrophy of aging. J Drugs Dermatol 6:123-128

28. Sculptra [package insert] (2009) Dermik Laboratories, Bridgewater

29. Levy RM, Redbord KP, Hanke CW (2008) Treatment of HIV lipoatrophy and lipoatrophy of aging with poly-L-lactic acid: A prospective 3-year follow-up study. J Am Acad Dermatol 59:923-933

30. Moyle GJ, Brown S, Lysakova L, Barton SE (2006) Long-term safety and efficacy of poly-L-lactic acid in the treatment of HIVrelated facial lipoatrophy. HIV Med 7:181-185

31. Beer K (2007) A single-center, open-label study on the use of injectable poly-L-lactic acid for the treatment of moderate to severe scarring from acne or varicella. Dermatol Surg 33(Suppl 2):S159-S167

32. Coleman SR, Grover R (2006) The anatomy of the aging face: volume loss and changes in 3-dimensional topography. Aesthetic Plast Surg 26:S4-S9

33. Mendelson BC (2001) Surgery of the superficial musculoaponeurotic system: principles of release, vectors, and fixation. Plast Reconstr Surg 107:1545-1552

34. Owsley JQ Jr, Zweifler M (2002) Midface lift of the malar fat pad: technical advances. Plast Reconstr Surg 110:674-685 